\title{
Impact of flow on oxygen dynamics in photosynthetically active sediments
}

\author{
Ulrike-G. Berninger ${ }^{1, *}$, Markus Huettel $^{2}$ \\ Max Planck Institute for Marine Microbiology, 'Microsensor Research Group, ${ }^{2}$ Department oi Biogeochemistry, \\ Celsiusstr. 1, D-28359 Bremen, Germany
}

\begin{abstract}
To assess the influence of boundary flow on interfacial oxygen flux in sediments inhabited by benthic phototrophs, we measured the oxygen distribution and the photosynthetic activity in an intertidal sandy core at flow velocities of $0,2,5,10$, and $15 \mathrm{~cm} \mathrm{~s}^{-1}$ in a laboratory flume. The impact of flow was large; the effects were reversible and most pronounced in the velocity range of 0 to $5 \mathrm{~cm} \mathrm{~s}^{-1}$ With increasing flow velocity, both the maximum oxygen concentration in the sediment and the oxygen penetration decreased significantly. The depth of the oxygen concentration maximum was shifted over $1 \mathrm{~mm}$ closer towards the sediment surface at the highest flow and the diffusive boundary layer was gradually compressed to a width of $0.2 \pm 0.1 \mathrm{~mm}$. The width of the photosynthetically active sediment layer decreased from $3.2 \pm 0.6 \mathrm{~mm}$ in stagnant water to $1.4 \pm 0.3 \mathrm{~mm}$ under flow, resulting in an overall reduction of gross photosynthesis. This is explained by a migration of the benthic algae (dominated by pennate diatoms) into deeper sediment layers under flow to avoid resuspension into the water, and thereby impairing photosynthesis. Despite the decrease in photosynthesis, the flux of oxygen into the water column did not change significantly, suggesting that advective processes enhanced the release of oxygen from the sediment under flow conditions. We concluded that boundary layer flow is an mportant factor controlling photosynthesis and oxygen release in shallow water sediments.
\end{abstract}

KEY WORDS: Oxygen - Boundary layer flow Benthic photosynthesis Intertidal permeable sediment Pore water advection. Benthic diatoms Planktonic phytoflagellates

\section{INTRODUCTION}

Shallow and intertidal photosynthetically active sediments are unique in the sense that they can serve as a source of oxygen (Sundbäck et al. 1991, Lassen et al. 1992). They harbour large populations of benthic phototrophic microorganisms, mostly diatoms, cyanobacteria and pigmented flagellates, which release oxygen into the overlying water and into the sediment (Revsbech et al. 1980, Revsbech \& Jørgensen 1983, Yallop et al. 1994, Reay et al. 1995). This contrasts with other sea beds, situated below the photic zone, where the supply of oxygen originates solely from the water column. The oxygen produced by benthic phototrophs is of pivotal importance for aerobic heterotrophic degradation processes within the sediment and for all aerobic

•E-mail: uberning@mpi-bremen.de organisms associated with the sediment (Fenchel 1969, Cammen 1991, Sundbäck et al. 1991, Berninger \& Epstein 1995).

Intertidal sediments are exposed to rapid environmental changes. Differences in the depth and turbidity of the overlying water and the corresponding light field in the salinity and temperature all affect the photosynthetic activity of the benthic autotrophic community (Admiraal 1977, Pinckney \& Zingmark 1991, Kühl \& Jørgensen 1994). Furthermore, these sediments are subjected to physical forces such as wave action and tidal currents. It has been shown that the resulting boundary layer flows affect the interfacial exchange processes between the sea floor and the overlying water column (Jørgensen \& Revsbech 1985, Gundersen \& Jørgensen 1990, Jørgensen \& Des Marais 1990, Booij et al. 1991). This is partially due to the reduction of the thickness of the diffusive boundary layer (DBL) with increasing boundary flow. The DBL is the layer of water 
covering all submersed surfaces, through which diffusion along a concentration gradient is the main transport mechanism for dissolved substances, such as oxygen (Jorgensen \& Revsbech 1985). In combination with the actual consumption and production rates in the sediment and the resulting gradients between water column and sediment, the thickness of the DBL is an important factor for the determination of the rate of transport and may therefore affect the total amount of solutes transported across the sediment-water interface. In permeable sea beds hydrodynamic mechanisms can enhance the exchange processes across the sediment/water interface (Huettel \& Gust 1992, Huettel et al. 1996, Lohse et al. 1996, Ziebis et al. 1996). When boundary layer flows interact with sediment topography, pressute ylduieuis à geinerated. These resuit in advective processes in addition to the diffusive exchange mechanisms, enhancing the interfacial transport of solutes (Forster et al. 1996, Ziebis et al. 1996).

The objective of our study was to investigate and quantify the effects of changes in boundary layer flow velocity on the oxygen dynamics in a photosynthetically active sandy sediment. We paid special attention to the distribution of oxygen and to photosynthetic activity within the sediment. Given the key role of oxygen for geochemical cycling, degradation of organic matter, and remineralization of nutrients, the understanding of the factors controlling benthic oxygen production and oxygen dynamics in the sediment is an important ecological concern.

\section{METHODS}

The sediment used for our experiments originated from a tidal flat on the German North Sea coast near Cuxhaven. We collected 8 cores (dimensions $15 \times 15 \times$ $20 \mathrm{~cm}$ ) within an area of $1 \mathrm{~m}^{2}$ several hundred meters from the beach, close to the low water line. The sediment consisted mainly of quartz sand, with a medium grain size of $200 \mu \mathrm{m}$, an average porosity (water content) of 0.38 and a permeability of $5.4 \times 10^{-12} \mathrm{~m}^{-2}$. At the time of sampling it showed a clear horizontal stratification with a ca $4 \mathrm{~cm}$ thick oxidized (lightly brown coloured) surface layer and a reduced (black) deeper layer. The sediment surface was covered by diatoms (see later for abundances and species composition) and some cyanobacteria (dominated by Oscillatoria), which formed a loose mat-type structure. Macro- and meiofauna were present, including the polychaetes Pygospio elegans, Spio filicornis, Heteromastus filiformis, Eteone longa and Nereis diversicolor, individuals of the crustacean Corophium volutator and Abra alba (mollusks). In order to minimize animal-mediated disruptions of the algal surface layer (through bioturba- tion and grazing activity) large specimens were carefully removed from the core with tweezers.

Immediately upon return to the laboratory, the 8 sediment cores were placed next to each other in the drop box $(60 \mathrm{~cm}$ length, $30 \mathrm{~cm}$ width, $20 \mathrm{~cm}$ depth) of a recirculating flume system $190 \mathrm{~cm}$ downstream from the start of the open channel). Within a few days the boundaries of the individual cores could no longer be detected. The flume (described in detail in Huettel et al. 1996) was made of clear acrylic and had an open channel section of $200 \mathrm{~cm}$ length, $30 \mathrm{~cm}$ width and $12 \mathrm{~cm}$ height. For oxygen flux measurements (see below), the flume could be completely sealed with a transparent acrylic lid. Test runs in the sealed flume filled solely with deoxygenated water confirmed that oxygen diffusion through the acrylic walls of the flume was negligible. The flume was filled with coarsely filtered water collected from the sampling site (total volume $160 \mathrm{l}$, salinity $15 \%$ o resulting in a water depth of $10 \mathrm{~cm}$ above the sediment core. The water level was kept constant throughout the entire experimental period, when water was lost due to evaporation it was replaced and the salinity adjusted. Water temperature was $17.5^{\circ} \mathrm{C}$, controlled by a cooling unit. $100 \%$ airsaturation of the overlying water corresponded to $272 \mu$ mol oxygen $1^{-1}$, calibrated in an air-saturated bubble chamber and confirmed by Winkler titration (Strickland \& Parsons 1972). The flow above the sediment was created by a rotating propeller, which was connected to a $12 \mathrm{~V}$ DC motor and located in the return circuit of the recirculating flume. An upstream collimator and a downstream sharp-crested weir prevented contact between the propeller-generated turbulence and the open channel section. The flow velocity could be adjusted in the range of 0 to $20 \mathrm{~cm} \mathrm{~s}^{-1}$ and was recorded with a MiniWater flow sensor mounted in the water ( $8 \mathrm{~cm}$ above the sediment surface) at the downstream end of the sediment core. When no experiments were run, the flow velocity remained at $2 \mathrm{~cm} \mathrm{~s}^{-1}$. The sequence of flow velocities selected was $0,2,5,10$, and $15 \mathrm{~cm} \mathrm{~s}^{-1}$ for Expt 1 (measurements of oxygen profiles), and $0,2,10$, and $15 \mathrm{~cm} \mathrm{~s}^{-1}$ for Expt 2 (estimations of photosynthetic activity). After the highest flow velocity was reached, the flow was turned off again, and control measurements under stagnant water were made. Each flow velocity was maintained for at least $12 \mathrm{~h}$ prior to taking measurements. Two sets of light bulbs with an emission spectrum improving plant growth were mounted over the whole length of the sediment core. The system was kept in a light regime of $12 \mathrm{~h}$ darkness and $12 \mathrm{~h}$ illumination (light intensity ca $120 \mu \mathrm{E} \mathrm{m}^{-2} \mathrm{~s}^{-1}$, measured with a Biospherical QSL-100 scalar irradiance sensor) all the time, irrespective of whether experiments were run. For photosynthesis measurements a spotlight was positioned close to the 
water surface. The light intensity at the sediment surface was thereby raised to ca $400 \mu \mathrm{E} \mathrm{m}^{-2} \mathrm{~s}^{-1}$ on an area of ca $20 \times 20 \mathrm{~cm}$.

To minimize artifacts due to sampling and transportation, the sediment core was allowed time to establish in the flume for 2 mo at a flow velocity of $2 \mathrm{~cm}$ $\mathrm{s}^{-1}$ before we started our first experiment. The sediment remained horizontally stratified. Between experiments, the sediment surface was allowed to evolve naturally. Gradually, a fluffy 1 to $2 \mathrm{~mm}$ thick layer of microalgae and detrital particles formed and covered the entire sediment surface. Some microtopography ( $z \leq 3 \mathrm{~mm}$ ) developed due to small burrowing fauna. The topography was manually smoothed $5 \mathrm{~d}$ prior to rumning an experiment. Within 2 to $3 \mathrm{~d}$, the surface was covered again with a loose layer of diatoms.

In our experiments, oxygen profiles and photosynthetic activity in the sediment were measured at a vertical resolution of $100 \mu \mathrm{m}$ employing Clark-type oxygen microelectrodes following the description in Jorgensen \& Revsbech (1988). At each respective flow velocity, between 3 and 5 replicate profiles were measured in locations with homogenous appearance of the surface, keeping minimum distance between the individual profiles. The oxygen concentration in the water column was constantly recorded by a commercially available oxygen electrode (WTW, Weilheim, Germany). In Expt 3, oxygen fluxes were assessed. They were calculated from the shallowest linear part of the slopes of the oxygen profiles immediately beneath the sediment surface (Revsbech \& Jorgensen 1986), assuming an oxygen diffusion coefficient in the sediment of $1.44( \pm 0.08) \times 10^{-5} \mathrm{~cm}^{-2} \mathrm{~s}^{-1}$ from a similar system described in the literature (Revsbech 1989 and references therein). This calculation only takes diffusive transport mechanisms between the sediment and the water column into account. In addition, in order to quantify the actual efflux of oxygen from the sediment into the water, water column recordings were performed when the lid of the flume was closed (Forster et al. 1996). For the estimation of the thickness of the DBL we measured the vertical extent of that part of the oxygen profile in which the water column oxygen concentration decreased as the electrode approached the sediment surface, but had not yet penetrated the sediment. The slope of the oxygen concentration in the DBL typically is different from the slope of the top part of the oxygen profile within the sediment (Jørgensen \& Des Marais 1990). Gross photosynthetic activity was measured using the dark/light shift method (Revsbech \& Jørgensen 1983. Glud et al. 1992). The period of darkness we applied lasted ca $5 \mathrm{~s}$, and for our calculations of the rate of photosynthesis in each distinct sediment layer we used the initial rate of oxygen decrease after darkening, which in our case corresponded to the decline during the first 2 to $3 \mathrm{~s}$ of darkness. Net photosynthesis of the photic zone, i.e. the combined flux upward and downward from the photosynthetically active zone, was calculated from oxygen concentration gradients within the sediment measured at steady state (Jensen \& Revsbech 1989). Respiration within the photic zone was calculated as the difference between gross and net photosynthesis (Revsbech \& Jorgensen 1983). (See also discussion later of possible shortcomings in the dark/ light shift method.) Three replicate photosynthesis measurements were conducted in locations with close proximity to each other at each flow velocity. Immediately after the completion of the measurements of photosynthesis at the highest flow velocity, the flow was turned off, and $12 \mathrm{~h}$ later a series of control measurements were performed in stagnant water (Expt 4).

In order to observe the short-term fluctuations of the oxygen dynamics in relation to the varying flow velocity we conducted 2 additional experiments (5a and b) on the same system at a later date. In Expt 5a, the flow velocity was alternated between 0 (no flow) and $10 \mathrm{~cm}$ $\mathrm{s}^{-1}$ in short time intervals ( $2 \mathrm{~h}$ stagnant water, followed by 2 h of flow, followed again by 2 h of no flow). Replicate oxygen profiles were taken during each phase. Expt 5b was aimed to demonstrate how fast-occurring changes in flow velocity affect the oxygen concentration at a given depth in the sediment. We started the measurement of an oxygen profile in stagnant conditions and left the electrode in the sediment layer of the oxygen concentration maximum. When the signal had stabilized, a slow flow velocity of $0.5 \mathrm{~cm} \mathrm{~s}^{-1}$ was created and left constant until the oxygen concentration at this sediment depth had again reached a stable value. The flow was then turned off, and again we waited for the oxygen signal to reach a steady state. Thereafter we applied a flow velocity of $1 \mathrm{~cm} \mathrm{~s}^{-1}$ and continued the measurements. This switch between flow and stagnant water was repeated 6 times altogether, and the velocity of the flow intervals was gradually increased (from 0.5 to $1,2,5,10$, and finally $15 \mathrm{~cm} \mathrm{~s}^{-1}$ ).

Abundances and distribution of planktonic and benthic phototrophs were studied in an identical system kept in the laboratory flume at a later date (Expt 6). This sediment core was exposed to the same light regime and the same sequence and intervals of flow velocity as in Expts 1 and 2. After the establishment of each velocity for ca $20 \mathrm{~h}, 3$ to 6 replicate water samples ( $8 \mathrm{ml}$ each) were collected from the center of the water column above the sediment core and fixed with an equal volume of $2.5 \%$ glutaraldehyde. After 40 h of exposure to the highest flow velocity $\left(15 \mathrm{~cm} \mathrm{~s}^{-1}\right)$ the flow was turned off and immediately afterwards 4 small sediment cores (inner diameter $1.25 \mathrm{~cm}$ ) were collected, and the 2 top layers were sliced off (top $1.6 \mathrm{~mm}$ of the sediment, and 1.6 to $4.1 \mathrm{~mm}$ ). Each slice was fixed with $4 \mathrm{ml}$ of $2.5 \%$ 


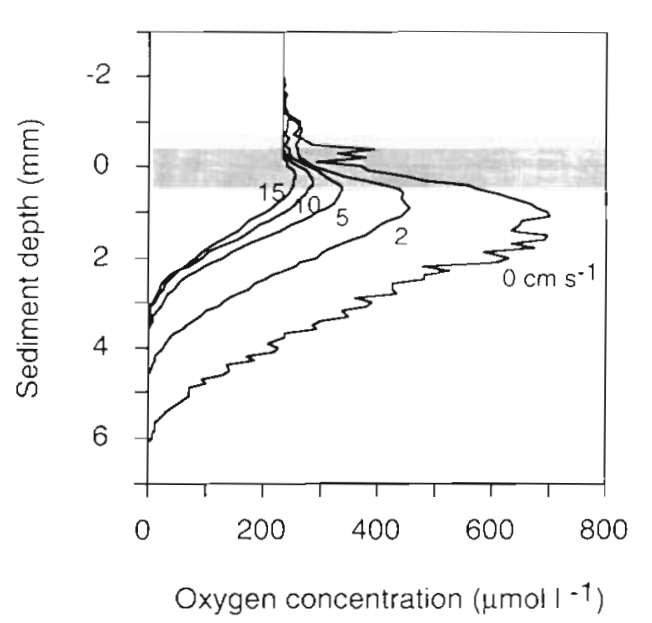

Fig. 1 Oxygen profiles measured at different flow velocities in an intertidal sediment core incubated in a laboratory flume system (Expt 1). Shaded bar indicates approximate location of sediment surface. Due to some microtopography on the sediment surface and a medium sand grain size of ca $200 \mu \mathrm{m}$ the surface of the sediment proper can only be estimated within a range of $\pm 200 \mu \mathrm{m}$. Flow velocity $\left(\mathrm{cm} \mathrm{s}^{-1}\right)$ is indicated near the respective oxygen profile glutaraldehyde. The holes left by the removal of samples were then filled with sand, the flow remained turned off and $48 \mathrm{~h}$ later a second set of sediment samples (avoiding the spots sampled before) exposed to stagnant water was collected and processed as described above. For the identification and the enumeration of algae, subsamples $4 \mathrm{ml}$ of the water samples, and $100 \mu$ ldiluted in $2.5 \mathrm{ml}$ of particle-free deionized water of the sediment samples) were stained with the fluorochrome DAPI (Porter \& Feig 1980), concentrated on a black polycarbonate membrane $(25 \mathrm{~mm}$ diameter, pore size $0.2 \mu \mathrm{m}$ ) and viewed with a Zeiss Axiophot epifluorescence microscope (magnification 1600x, filter set No. 09: BP 450-490, FT 510, LP 520). Algae were identified by their characteristic red chlorophyll a autoflicorescence. In addition, the abundanco of largo (area $\geq 100 \mathrm{\mu m}^{-2}$ ) organic particles was monitored in the water column samples. These particles can easily be recognized by their shape, structure and by their characteristic yellow fluorescence in DAPl-stained samples excited with UV light (Zeiss filter set No. 01: BP 365/12, FT 395, LP 397).
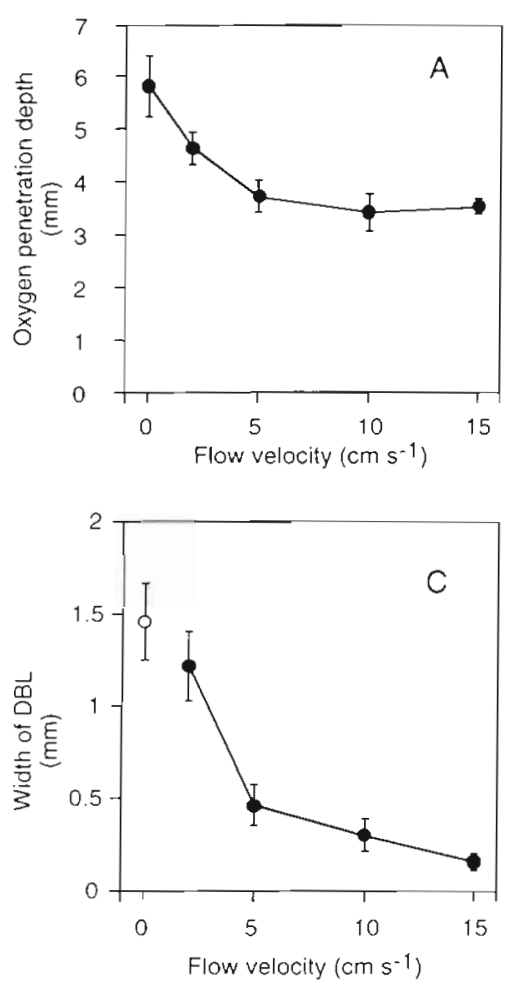
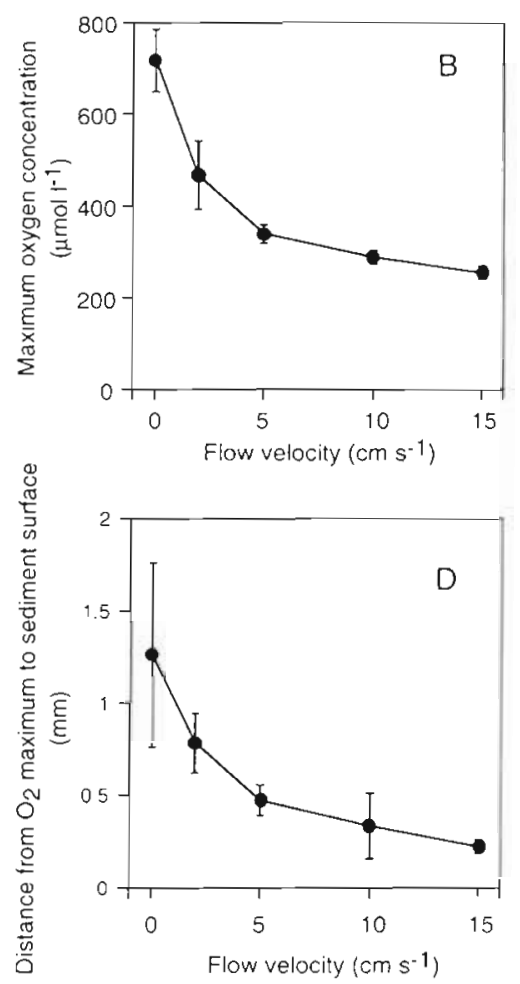

Fig. 2. Correlation between flow velocity and (A) the oxygen penetration depth, (B) oxygen concentration maximum, (C) width of the diffusive boundary layer DBL, and (D) distance of the oxygen maximum from the sedıment surface measured in an intertidal sediment core (Expt 1). Values represent means of 3 to 5 replicate measurements $( \pm 1 \mathrm{SD})$. Theoretically, the thickness of the DBL is infinite in stagnant water, but due to some heat convection induced by illumination we measured a value of $1.5 \pm 0.2 \mathrm{~mm}$ without actual flow. Therefore this data point ( $C$, open symbol) is not connected to the other values

\section{RESULTS}

\section{Expt 1}

In the light, benthic photosynthesis clearly influenced the oxygen conditions in our experimental sediment core. The shapes of oxygen profiles measured were typical for a sea bed inhabited by phototrophic microorganisms concentrated in a specific sediment layer (i.e. maximum oxygen concentration underneath the sediment surface and gradually decreasing concentrations towards deeper sediment layers). The oxygen profiles drastically changed with respect to the flow velocity (Fig. 1). With the flow velocity increasing from 0 to $15 \mathrm{~cm} \mathrm{~s}^{-1}$, the oxygen penetrated $2.3 \mathrm{~mm}$ less into the sediment $[5.8 \pm 0.6 \mathrm{~mm}$ (mean $\pm \mathrm{SD}$ ) vs $3.5 \pm 0.15 \mathrm{~mm}$, the oxygen concentration maximum decreased almost 3 -fold (from $717.7 \pm 69.1$ to $256.6 \pm 13.6 \mu \mathrm{mol}$ $\left.\mathrm{l}^{-1}\right)$. The thickness of the DBL was reduced to $0.2 \pm 0.1 \mathrm{~mm}$ at a velocity of $15 \mathrm{~cm} \mathrm{~s}^{-1}$ (Fig. 2A-C). In stagnant water, the thickness of the DBL theoretically equals the water depth, but due to some heat convection induced by illumination we measured a value of $1.5 \pm 0.2 \mathrm{~mm}$ without flow. The distance between the 
depth of the oxygen concentration maximum and the sediment surface decreased, i.e. the highest oxygen concentration was shifted over 1 mm closer towards the surface at higher flow velocities (from $1.3 \pm 0.5$ to $0.2 \pm$ $0.1 \mathrm{~mm}$ below the surface; Fig 2D). Due to the coarse grain size, the location of the sediment surface could only be determined with a precision of $\pm 200 \mu \mathrm{m}$. In all cases the most dramatic changes of the oxygen profiles were recorded in the flow velocity range of 0 to $5 \mathrm{~cm} \mathrm{~s}^{-1}$ In stagnant water oxygen bubbles developed within the uppermost sediment layer and the benthic diatoms formed small 'towering clusters' (ca $500 \mu \mathrm{m}$ in height) on the sediment surface. After the onset of flow the algae gradually resumed a horizontal position, the surface became smoother, and the bubbles disappeared
In addition to the changes in the values of the photosynthesis parameters, the shape of the photosynthesis profiles changed considerably as the flow velocity was increased. In stagnant water, the benthic diatoms formed 'towering clusters', i.e. they did not lie horizontally flattened on top of the sediment surface but they assumed an almost upright position thus extending their photosynthetic activity ca $500 \mu \mathrm{m}$ into the water column. Below the sediment surface, there was a gradual increase of photosynthetic activity over $800( \pm 100) \mu \mathrm{m}$ until the sediment layer of the maximal oxygen production was reached. This increase became less and less pronounced as the flow velocity was raised, the top part of the profile became flatter, and the photosynthetic maximum was shifted up-
Expt 2

In order to understand the oxygen profiles obtained from the experiment described above, we also determined the photosynthetic activity at different flow velocities. Photosynthesis clearly changed with flow (Fig. 3). The vertical extent of the sediment layer in which oxygen was produced decreased from $3.2 \pm 0.6 \mathrm{~mm}$ in stagnant water to $1.4 \pm$ $0.3 \mathrm{~mm}$ at $2 \mathrm{~cm} \mathrm{~s}^{-1}$ and did not cilange significantly further at higher velocities (Figs. 3 \& 4A). The maximum pinotosynthetic activity showed no statistically significant change with increasing flow velocity faverage production across the whole range of flow velocities was $16.3 \pm 2.7 \mu \mathrm{mol}$ oxygen $\mathrm{cm}^{-3}$ $\mathrm{h}^{-1}$; Fig. 4B). Depth-integrated gross photosynthesis decreased with the onset of flow $12.0 \pm 0.5 \mu \mathrm{mol}$ oxygen $\mathrm{cm}^{-2}$ $\mathrm{h}^{-1}$ in stagnant water compared to $0.9 \pm$ $0.3 \mu \mathrm{mol} \mathrm{cm}^{-2} \mathrm{~h}^{-1}$ at $2 \mathrm{~cm} \mathrm{~s}^{-1}$ and no further significant change at higher velocities: Fig. 4C). Both the absolute values for net photosynthesis and for respiration also decreased when flow was started, whereas respiration expressed as percentage of gross photosynthesis remained relatively constant. Irrespective of flow velocity, over half of the oxygen produced (58.2 \pm $12.0 \%$ ) was instantly respired or otherwise consumed within the sediment and was not available for efflux from the photosynthetically active zone (Fig. 4D)
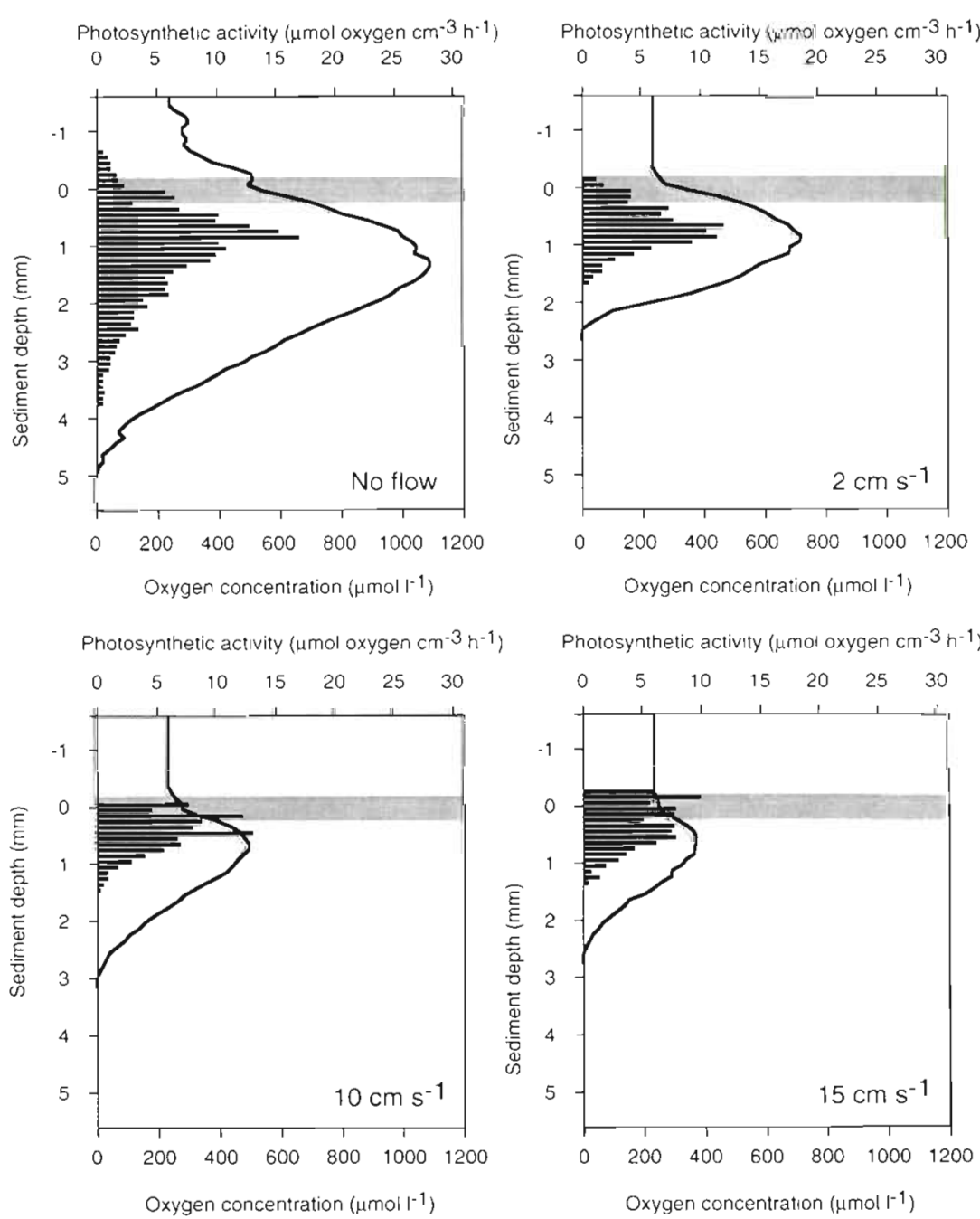

Fig. 3. Oxygen profiles (solid line) and photosynthetic activity (solid bars) measured in an intertidal sediment at different flow velocities employing the dark/light shift method (Expt 2). Shaded bar indicates approximate location of sediment surface (see Fig. 1 legend). Each data set represents the mean of 3 replicate measurements. See text for further explanations 

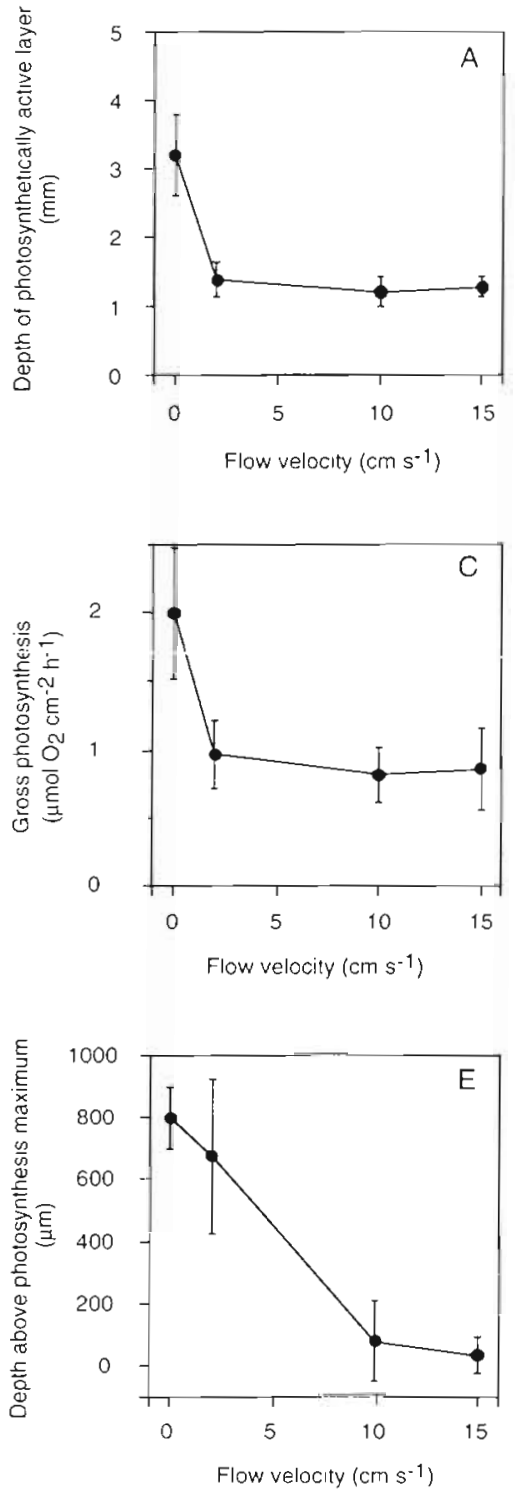
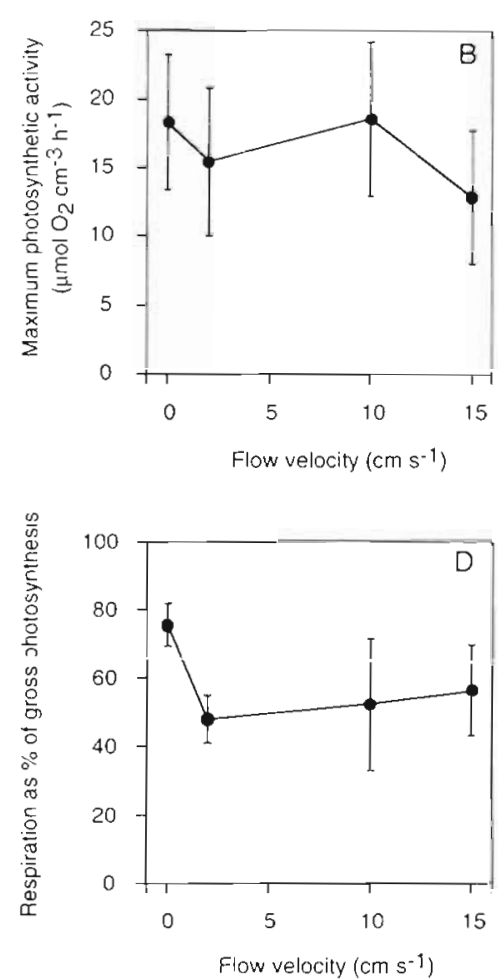

Fig. 4. Correlation between flow velocity and (A) vertical extent of photosynthetically active layer, (B) maximum photosynthetic activity, (C) gross photosynthesis, (D) respiration expressed as \% of gross photosynthesis and (E) vertical extent of the photosynthetically active layer above the photosynthesis maximum in an intertidal sediment (Expt 2). Values represent the mean of 3 replicate measurements $( \pm 1 \mathrm{SD})$
Expt 3

Based on the initial slopes of the oxygen profiles underneath the sediment surface and an oxygen diffusion coefficient suggested in Revsbech (1989) for sediments $\left(\Phi D_{\mathrm{S}}=1.44 \pm 0.08 \times 10^{-5} \mathrm{~cm}^{2}\right.$ $\mathrm{s}^{-1}$ ), we calculated the flux of oxygen from the sediment into the water column solely due to molecular diffusion at the different flow velocities. Based on these calculations, the amount of oxygen transported upwards decreased gradually with increasing flow velocity and was $50.6 \pm 10.6 \%$ less at the highest flow velocity $\left(15 \mathrm{~cm} \mathrm{~s}^{-1}\right)$ than in stagnant water (Fig. 5). We obtained a similar result when we based our calculations on the slope of the oxygen profiles within the DBL and used a diffusion coefficient for oxygen in the water $\left(\Phi D_{W}=1.91 \times\right.$ $10^{-5} \mathrm{~cm}^{2} \mathrm{~s}^{-1}$, allowing for temperature and salinity. In parallel, we determined the actual oxygen flux into the water by monitoring the change of oxygen concentration in the water column of the sealed flume over the same range of flow velocities. These measured values indicated a different trend. Compared to the oxygen concentration in stagnant water the oxygen concentration did not change significantly with increasing flow. This implied that an additional transport process other than molecular diffusion released the oxygen from the sediment to the water at the higher flow velocities. With an ANCOVA (analysis of covariance) we could demonstrate that the interaction between the flow velocity wards, to a point where it was recorded directly at the sediment surface (measured at the highest velocity; Figs. 3 \& $4 \mathrm{E}$ ).

The oxygen profiles obtained simultaneously with the measurements of photosynthetic activity and their relative changes with changing flow velocity were in agreement with the oxygen profiles obtained in Expt 1 (Figs. 1 \& 3). The oxygen concentration maximum gradually decreased from ca $1100 \mu \mathrm{mol} \mathrm{l}^{-1}$ in stagnant water to less than $400 \mu \mathrm{mol}^{-1}$ at the highest flow velocity $\left(15 \mathrm{~cm} \mathrm{~s}^{-1}\right)$, and the oxygen penetration depth decreased from ca 5 to less than $3 \mathrm{~mm}$. The distance between the sediment surface and the depth of the oxygen maximum at high flow was less than half that in stagnant water $(0.7$ and $1.5 \mathrm{~mm}$, respectively). and the change of the diffusive flux from the sediment upwards was statistically different ( $p=0.0077$ ) to the interaction between the flow velocity and the actual concentration change in the water column.

\section{Expt 4}

We confirmed that the changes in the oxygen and photosynthesis dynamics we recorded were reversible by repeating our measurements in stagnant water $12 \mathrm{~h}$ after the measurements at the highest velocity $115 \mathrm{~cm}$ $\mathrm{s}^{-1}$ ) had been taken. The results of these control measurements showed an increase of the vertical extent of the photosynthetically active sediment layer compared to the last flow velocity employed $(1.7 \pm 0.1 \mathrm{~mm})$, and a 
strong increase of the maximum photosynthetic activity $\left(32.7 \pm 1.7 .2 \mu \mathrm{mol}\right.$ oxygen $\left.\mathrm{cm}^{-3} \mathrm{~h}^{-1}\right)$. Gross photosynthesis reached a value close to that obtained in the initial measurements in stagnant water $(2.2 \pm 1.21 \mu \mathrm{mol}$ oxygen $\mathrm{cm}^{-2} \mathrm{~h}^{-1}$ ) and the shape of the photosynthesis profile had started to revert back (data not shown)

\section{Expt 5}

The impact of boundary layer flow on the oxygen profiles was also observed when the switches from flow (here: $10 \mathrm{~cm} \mathrm{~s}^{-1}$ ) to stagnant water and back to flow were executed over much shorter periods of time than in the experiments described above (Expt 5a). Within 2 to $3 \mathrm{~min}$ after turning off the water flow, oxygen maximum concentration increased by ca $300 \mu \mathrm{mol} \mathrm{l}^{-1}$, and continued to increase over the following $1 \mathrm{~h}$. Upon starting the water flow again, this effect was reversed and after 25 min the maximum had decreased again to values close to those of the initial situation (data not shown). From the recordings of the oxygen concentration with an electrode fixed at one sediment depth we could demonstrate the effect of the flow velocity on the oxygen concentration in a given photosynthetically active sediment layer (Fig 6). At the same depth, the oxygen concentration was always considerably lower when flow was applied than it was in stagnant water. After changed flow conditions, a new steady state established itself within ca 10 to $25 \mathrm{~min}$. When comparing the intermittent periods of stagnant water, the maximum concentration also gradually decreased, but levelled off at flow velocities $\geq 5 \mathrm{~cm} \mathrm{~s}^{-1}$.

\section{Expt 6}

The phototrophic communities in the water overlying the sediment and in the sediment proper consisted of 2 distinctly different groups. The planktonic algae comprised mostly small $(\leq 5 \mu \mathrm{m})$ phytoflagellates, whereas the benthic phototrophs were completely dominated by larger diatoms (ca 20 to $\geq 100 \mu \mathrm{m}$ in length) such as Coscinodiscus, Achnanthes, Amphora, Cocconeis, Navicula, Nitzschia and Opephora spp. Irrespective of the flow velocity, the 2 communities did not mix.

The abundances of planktonic phytoflagellates were relatively high (ca 2 to $3 \times 10^{5}$ cells $\mathrm{ml}^{-1}$ ). These numbers did not increase with higher flow velocity, but instead showed a small but statistically significant decline (linear regression: slope $=-4.29, \mathrm{r}^{2}=0.75$, implying that compared to the abundance of algae in the stagnant water column, their numbers had de-

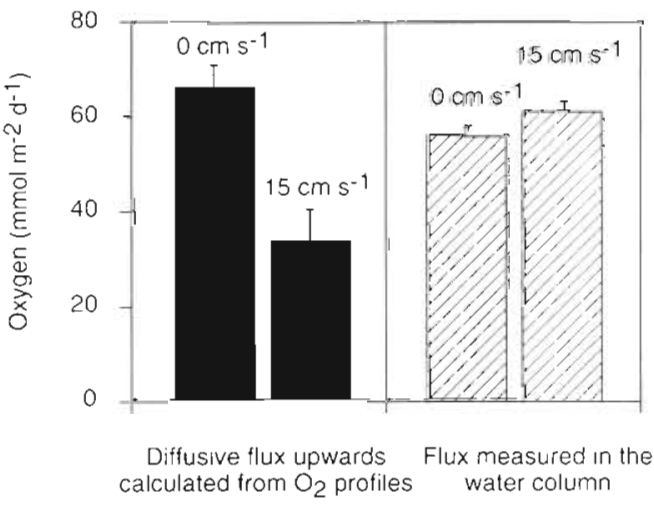

Fig. 5. Diffusive oxygen flux from the sediment into the overlying water calculated as a function of the oxygen profile in the sediment (solid bars) and measured directly as an increase of the oxygen concentration in the water column (hatched bars) (Expt 3). Interactions between flow velocity and source of oxygen were statistically different $(\mathrm{p}=0.0077)$. See text for further details

creased by ca $20 \%$ at the highest flow velocity; Fig. 7). We did not observe any resuspension of benthic algae into the water column; the number of diatoms in the water column remained negligible at all times. However, at flow velocities of $10 \mathrm{~cm} \mathrm{~s}^{-1}$ and above, macroscopically visible particles were torn off from the sediment surface and transported into the water column. In our microscopical analysis these particles were identified as DYP (DAPI Yellow Particles; Mostajir et al. 1995), probably consisting of labile detritus. On the filter preparations for enumerations, smaller fractions of these particles were present (due to the mixing of the fixed samples the particles had fallen apart) and with increasing flow velocity, their abundance increased. Most of the DYPs showed no physical association with

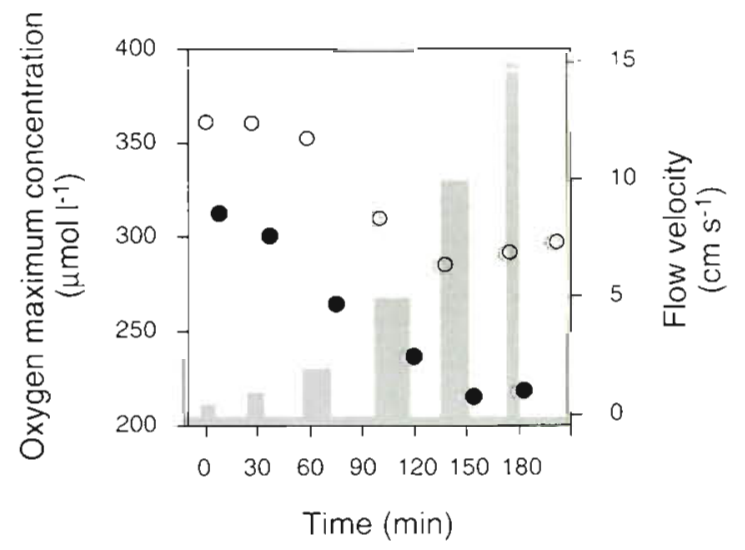

Fig. 6. Maximum oxygen concentration at a constant sedument depth in stagnant water (open symbols) and under flow (closed symbols). Periods of no-flow and flow were oscillated; from one flow-period to the next the flow velocity was gradually increased (shaded bars) (Expt 5b). See text for further explanation 


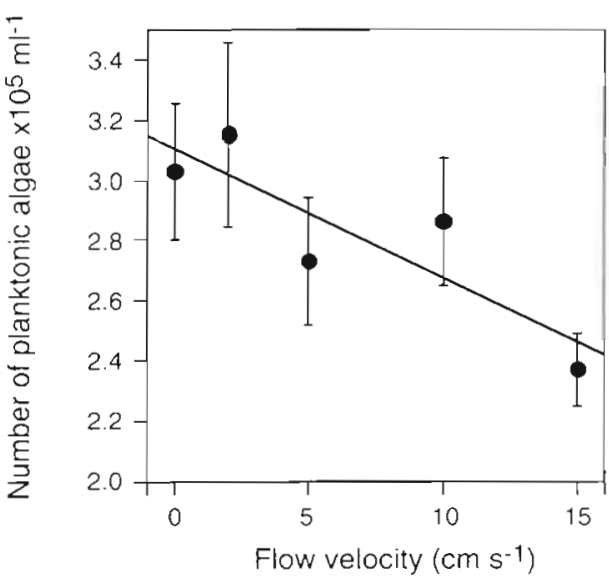

Fig. 7 Abundance of phototrophic organisms from the water column above an intcrtidal sodiment corc at different flow velocities (Expt 6). Values represent the mean of 3 to 6 replicate samples collected $( \pm 1$ SD). Solid line represents a lineat regression with the equation: $f(x)=-4.29 \times 10^{3} x+3.1 \times 10^{5}$; $r^{2}=0.75$

any of the benthic organisms present in our sediment, but in some cases bacteria were attached to them.

The distribution of benthic algae in the oxygenated sediment layer varied between cores exposed to stagnant water or to flow (Fig. 8). This difference was most pronounced concerning the relative abundances of algae at the sediment surface compared to those in the deeper layer. Absolute abundances in the surface layer were similar in both cases $\left(6.0 \pm 2.1 \times 10^{6}\right.$ in stagnant conditions and $4.5 \pm 1.1 \times 10^{6}$ ind $\mathrm{cm}^{-3}$ at $15 \mathrm{~cm} \mathrm{~s}^{-1}$ ), but in stagnant water the numbers of algae in the deeper sediment layer decreased drastically. In contrast, under flow their numbers did not change signifi-

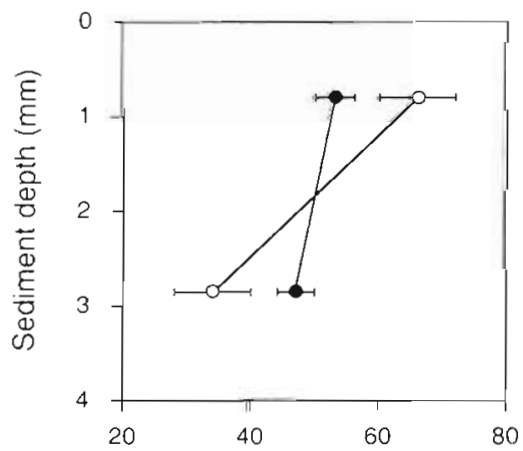

Relative abundance of benthic algae $\mathrm{cm}^{-3}(\%)$

Fig. 8. Abundance and vertical distribution of benthic phototrophs in the top 2 layers of the sediment $(0$ to $1.6 \mathrm{~mm}$ and 1.6 to $4.1 \mathrm{~mm}$ ) of an intertidal sediment core exposed to stagnant water (0) and a flow velocity of $15 \mathrm{~cm} \mathrm{~s}^{-1}$ ( Data are expressed in \%, where $1.00 \%=$ sum of the numbers of algae from both layers. Values represent the mean of 6 replicate samples collected ( $\pm 1 \mathrm{SD}$ ) cantly, implying that the algae moved away from the sediment surface when flow was present. Expressed as $\%$ of the sum of algae found in the 2 layers, only $34 \pm$ $6 \%$ of the algae were present in the second layer in stagnant water, whereas under flow conditions $47 \pm$ $3 \%$ of the algae dwelled in the deeper sediment.

\section{DISCUSSION}

Our experiments clearly showed that flow of the water overlying photosynthetically active sediments affected both the oxygen concentration profiles within the sediment and the photosynthetic oxygen production. Due to the photosynthetic activity within the sediment the oxygen concentration at and just undcrncath the sediment surface was higher than that in the overlying water. Increasing flow velocities resulted in a reduction of the oxygen concentration and in the vertical extent of the oxygenated zone in the sediment (Fig. 1). This is partially explained by the reduction of the thickness of the diffusive boundary layer (DBL) at higher flow velocities (Jørgensen \& Revsbech 1985 , Gundersen \& Jørgensen 1990, Jørgensen \& Des Marais 1990, Glud et al. 1994). (See also Shum 1995 for the discussion of advective transport within a linear part of the oxygen profile.) The diffusive path was shorter at high flow velocities compared to stagnant water, hence the flux of oxygen from the sediment into the water was higher With increasing flow, both the concentration of oxygen in the sediment and its penetration depth decreased, whereas the concentration of oxygen in the water column of the sealed flume remained the same (Fig. 5). However, when we used the slopes of the oxygen profiles measured in the sediment or in the DBL to calculate the diffusive export of oxygen from the sediment into the water (Glud et al. 1995) we obtained a different result: the upward flux of oxygen should have substantially decreased with increasing flow velocity (Fig. 5). This discrepancy implies that the oxygen in the water column did not stem from diffusive flux out of the sediment. We concluded that advective transport in addition to diffusion became effective at higher flow velocities. We ruled out increased water column oxygen production, because the abundance of phototrophic organisms in the water column did not rise but instead went down slightly with increased flow velocity. Since we did not record a concurrent increase in phytoflagellate abundance in the sediment we assume that some of the planktonic algae either died in response to the changed flow conditions or that they settled on the surfaces within the flume system. Under none of the flow conditions we applied were any benthic algae resuspended into the water (Fig. 7) This is in agreement with results obtained by Denis et al. (1996), 
who found that resuspension of benthic algae only commenced at flow velocities exceeding $15 \mathrm{~cm} \mathrm{~s}^{-1}$ In stagnant water the efflux of oxygen into the water column is largely determined by molecular diffusion, and therefore strongly affected by the thickness of the DBL. This explains why in that situation there is good agreement between both our approaches

In a series of studies, Huettel \& Gust (1992), Huettel et al. (1996), Lohse et al. (1996) and Ziebis et al. (1996) demonstrated the effects of advective transport mechanisms driven by pressure gradients that build up at sediment topography exposed to boundary layer flows. Due to these pressure gradients, solutes are forced into permeable sediments upstream of protruding surface structures and forced upwards into the water column on the backside of this topography, resulting in an advective flushing of the upper sediment layers. The advection supplements diffusive transport, i.e. when both transport mechanisms operate simultaneously, the amount of solutes crossing the sediment-water interface increases. Advective processes are significant even when sediment topography is in the millimeter range. We attempted to smooth out the core surface before taking our measurements, but some irregular elevations and depressions with a vertical extent of 1 to $3 \mathrm{~mm}$ were still present. The shapes of our oxygen profiles indicated that this microtopography of the sandy sediment was sufficient to induce advective transport of oxygen at the higher flow velocities, through which oxygen was released from the permeable sediment. The almost vertical orientation of the subsurface section of the oxygen profiles measured at $15 \mathrm{~cm} \mathrm{~s}^{-1}$ flow velocity, the displacement of the depth of the oxygen maximum towards the sediment surface, and the decrease of the maximum oxygen concentration all indicate advective transport within the sediment surface layer

The decrease of oxygen we measured in the sediment at higher flow velocities was not solely due to a more effective export of oxygen. Our measurements of photosynthetic activity over a range of flow speeds indicated that the absolute amount of oxygen produced in the sediment also decreased with the onset of flow (Figs. $3 \& 4$ ). This reduction in photosynthesis was due to a combination of a behavioural response of the benthic phototrophs to changed flow conditions and to the flow effects on their chemical environment.

A well-known protection mechanism for avoiding detachment from the sediment surface and resuspension into the water column when exposed to flow (Heckman 1985) or to escape other adverse influences, such as strong light (Garcia-Pichel et al. 1994) or UV-B radiation (Bebout \& Garcia-Pichel 1995) is the vertical migration of a part of the benthic diatom and cyanobacterial population into deeper sediment layers. By this vertical migration, the phototrophs may leave the sediment layer with the optimal conditions for photosynthesis, for example concerning the light regime (Kühl \& Jørgensen 1994), and thus reduce their photosynthetic efficiency. This is consistent with our findings. Under stagnant conditions, we found the highest abundance of benthic algae in the sediment surface layer (top $1.6 \mathrm{~mm}$ of the sediment) to be the same layer where the highest photosynthetic activity was recorded. In the deeper sediment layer (1.6 to $4.1 \mathrm{~mm}$ below the surface) this number had decreased significantly. In contrast, under flow the numbers of diatoms present in both distinct sediment layers were similar to each other, i.e. a relatively larger fraction of the total benthic algal community had migrated to a deeper sediment layer, less advantageous for photosynthetic activity. In addition, under flow conditions the diatoms living directly at the sediment surface could not remain in their upright (towering) position (see above) but instead lay horizontally flattened on the sediment. This probably resulted in a stronger shading effect for the phototrophs in deeper sediment layers, thus further impairing their photosynthetic activity.

Furthermore, the nutrient supply in the uppermost layers of the sediment also changed due to the increased advective flushing at higher flow velocities (Huettel et al. 1996). In our study, in the same fashion as the oxygen that was produced close to the sediment surface was exported to the water column at a higher rate in flowing than in stagnant water, the pore water from the sediment immediately underneath the sediment surface (presumably with higher concentrations in dissolved inorganic nutrients and $\mathrm{CO}_{2}$ compared to the flume water) was flushed from the sediment as the boundary flow velocity increased and replaced by nutrient-poor fluid originating from the overlying water (Huettel et al. 1996). The removal of these critical substances from the sediment may thus have further impaired photosynthetic activity in the deeper sediment layers and enhanced the reduction of the vertical extent of the photosynthetically active sediment layer. However, the diatoms dwelling directly at the sediment surface probably benefited from this increased nutrient release, indicated by the increase of their photosynthetic activity (Fig. 4E)

Another possible factor affecting the oxygen dynamics and the photosynthesis in our system could have been the advective transport of hydrogen sulphide from deeper sediment layers towards the surface (Huettel \& Gust 1992, Huettel et al. 1996). However the oxygen profiles measured in conjunction with the photosynthesis measurements indicate that at all flow velocities oxygen was present at least $1 \mathrm{~mm}$ below the deepest layer with measurable oxygen production 
thereby forming a buffer between hydrogen sulphide the phototrophs and the sediment surface

Our results are supported by the findings of Kühl et al. (1996), who reported on measurements of oxygen profiles and the photosynthetic performance of an epilithic cyanobacterial biofilm, dominated by the filamentous Oscillatoria sp., under varying flow conditions. They observed a similar correlation between the flow velocity and the oxygen profiles to that found in our study. The photosynthetic activity remained relatively stable in the biofilm, irrespective of flow velocity. This discrepancy with our results is due to the different physical consistency of a biofilm compared to an intertidal sediment and to the different composition of the phototrophic community.

The results from nur rontrol measurements and from the short-term changes in flow velocity emphasized the dynamic properties of the system and demonstrated that there was an almost immediate response to changed flow conditions, which could be reversed just as fast. The most dramatic changes in the sediment oxygen conditions we observed occurred over a very small range of flow velocities, namely between stagnant water and a flow speed of $5 \mathrm{~cm} \mathrm{~s}^{-1}$. At higher velocities, the flow effects levelled off. This indicates that low flow velocities and small changes therein can substantially alter the environment for all organisms that need (or avoid) oxygen. On a large scale, this switch from flow to no-flow represents a division between situations at low tide or in tidal pools, where there is no water movement above the sediment surface, in contrast to high tide, where due to the tidal movement and wind-induced flow the water is constantly moving. Experimentally we tried to mimic this effect by conducting control measurements in stagnant water ca $12 \mathrm{~h}$ after the sediment had been exposed to a flow velocity of $15 \mathrm{~cm} \mathrm{~s}^{-1}$. Both the oxygen and the photosynthesis profiles had completely changed again and approximated the conditions recorded in the initial stagnant water phase. But critical changes in flow velocity can also occur on a much smaller temporal scale. On a typical intertidal flat, the sediment is constantly exposed to changes in velocity in the range of 0 to $5 \mathrm{~cm} \mathrm{~s}^{-1}$. We simulated this scenario in experiments where the switch between no-flow and flow was induced in short intervals. The data in Fig. 6 demonstrate that even a very low flow velocity of $0.5 \mathrm{~cm} \mathrm{~s}^{-1}$ can substantially change the oxygen concentration at a given depth in the sediment. Irrespective of the absolute magnitude of the flow velocity, the difference between the maximum oxygen concentration in stagnant water and under flow remained relatively constant. The highest concentration reached within the stagnant water intervals also decreased gradually, indicating that biological changes (algal migration and compaction) and changes in the pore water composition had commenced, which could not be completely reversed in the relatively short intervals without water movement. These immediate chemical changes within the sediment and in the oxygen transport across the sediment-water interface demand special adaptations from the organisms inhabiting these systems, manifested either in a high tolerance to changing conditions or in the capability to be highly motile and flexible. This is especially important for small organisms such as ciliated protozoa that orient themselves along chemical gradients. In order to remain at optimum oxygen conditions they are constantly forced to move within the sediment (Berninger \& Epstein 1995).

Although our results can be explained by a combination of the biological, hydrodynamical and chemical responses to flow, there might be an additional bias due to the method we used for the determination of photosynthetic activity. This method (described in detail in Revsbech \& Jørgensen 1983) is based on microelectrode measurements of the change in oxygen concentration in a given sediment layer when photosynthesis is stopped by darkening after a period in the light. The method relies on 3 basic assumptions: (1) the oxygen profiles are at a steady state, (2) oxygen respiration remains the same irrespective of the light conditions, and (3) diffusion is the main transport mechanism for oxygen away from the point where it is produced. If one of these assumptions is not met, the results obtained may be questionable. We discussed above that in our sediment core advection could create an important additional pathway for the transport of oxygen between the top sediment layers and the overlying water. It is possible that this 'enhanced' oxygen export, integrated over a larger sediment volume than sole diffusion, leads to an overestimation of the photosynthetic rate. However, the amount of solutes transported advectively should be the same in the light as in darkness, hence the relative concentration changes should remain unaffected. Likewise, if under flow hydrogen sulphide had been advectively exported from deeper sediment layers and had served as an additional sink for oxygen, this would have led to an overestimation of the photosynthetic rates we calculated. It should be kept in mind, though, that in systems subjected to flow it becomes very important to measure the slope of the oxygen decrease immediately after the onset of darkness, since with time the discrepancy between the amount of oxygen that is transported diffusively and advectively will increase. Despite these potential problems we believe that our general findings are not biased by such a methodological artifact, since our results indicate a decrease rather than an increase of the photosynthetic activity. This artifact may, however, be the reason for the fact that. 
we see elevated photosynthetic activity at high flow velocities directly at the sediment surface, in the layer where advective transport is likely to be strongest. It would be desirable to develop a method that is completely independent of flow-induced changes in the parameters that serve to calculate photosynthetic activity. For example, a much higher spatial and especially temporal resolution of photosynthesis measurements would be helpful. Furthermore, in instances where flux rates cannot be measured directly, the application of a reaction-diffusion model such as that suggested by Epping \& Jørgensen (1996) may be appropriate.

Given the pivotal importance of oxygen for the biological, chemical and geological processes within sediments, the factors controlling the production and transport of oxygen need to be fully understood. Our work demonstrates the strong impact of the boundary flow on both oxygen production and on interfacial oxygen flux in photosynthetically active sediments. We conclude that the knowledge of the magnitude and of the variability of boundary layer flows is indispensable when attempting to assess sediment-water oxygen fluxes in such systems.

Acknowledgements. We are grateful to A. Glud, A. Eggers and $G$. Eickert for the manufacturing of oxygen microsensors, to S. Forster for contribution to the data on water column oxygen consumption, and to $S$. Wickham for help with statistical analysis of the data. We thank M. Kühl, S. Wickham, S. Forster, E. Epping, R. Glud, F. Neudörfer, J. Meyercordt and 2 anonymous reviewers for their valuable comments on the discussion of our results

\section{LITERATURE CITED}

Admiraal W (1977) Salinity tolerance of benthic estuarine diatoms as tested with a rapid polarographic measurement of photosynthesis. Mar Biol 39:11-18

Bebout BM, Garcia-Pichel F (1995) UV B-induced vertical migration of cyanobacteria in a microbial mat. Appl Environ Microbiol 61:4215-4222

Berninger UG, Epstein SS (1995) Vertical distribution of benthic ciliates in response to the oxygen concentration in an intertidal North Sea sediment. Aquat Microb Ecol 9:229-236

Booij K, Helder W, Sundby B (1991) Rapid redistribution of oxygen in a sandy sediment induced by changes in the flow velocity of the overlying water. Neth $\mathrm{J}$ Sea Res 28 : $149-165$

Cammen LM (1991) Annual bacterial production in relation to benthic microalgal production and sediment oxygen uptake in an intertidal sandflat and an intertidal mudflat. Mar Ecol Prog Ser 71:13-25

Denis L, Grenz C. Plante-Cuny MR (1996) Etude expérimentale de la remise en suspension du microphytobenthos. C R Acad Sci Ser [III] 319:529-535

Epping EHG, Jørgensen BB (1996) Light-enhanced oxygen respiration in benthic communities. Mar Ecol Prog Ser 139:193-203

Fenchel T (1969) The ecology of marine microbenthos IV. Structure and function of the benthic ecosystem, its chem- ical and physical factors and the microfauna communities with special reference to the ciliated protozoa. Ophelia 6 : $1-182$

Forster S, Huettel M, Ziebis W (1996) Impact of boundary layer flow velocity on oxygen utilization in coastal sediments. Mar Ecol Prog Ser 143:173-185

Garcia-Pichel F, Mechling M, Castenholz RW (1994) Diel migrations of microorganusms within a benthic hypersaline mat community. Appl Environ Microbiol 60: $1500-1511$

Glud RN, Gundersen JK, Revsbech NP, Jorgensen BB (1994) Effects on the benthic diffusive boundary layer imposed by microelectrodes. Limnol Oceanogr 39:462-467

Glud RN, Jensen K, Revsbech NP (1995) Diffusivity in surficial sediments and benthic mats determined by use of a combined $\mathrm{N}_{2} \mathrm{O}-\mathrm{O}_{2}$ microsensor. Geochim Cosmochim Acta 59:231-23?

Glud RN, Ramsing NB, Revsbech NP (1992) Photosynthesis and photosynthesis-coupled respiration in natural biofilms quantified with oxygen microsensors. J Phycol 28:51-60

Gundersen JK, Jørgensen BB (1990) Microstructure of diffusive boundary layers and the oxygen uptake of the sea floor. Nature 345:604-607

Heckman CW (1985) The development of vertical migration patterns in the sediments of estuaries as a strategy for algae to resist drift with tıdal currents. Int Rev Ges Hydrobiol 70:151-164

Huettel M, Gust G (1992) lmpact of bioroughness on interfacial solute exchange in permeable sediments. Mar Ecol Prog Ser 89:253-267

Huettel M, Ziebis W, Forster S (1996) Flow-induced uptake of particulate matter in permeable sediments. Limnol Oceanogr 41:309-322

Jensen J, Revsbech NP (1989) Photosynthesis and respiration of a diatom biofilm cultured in a new gradient growth chamber. FEMS Microb Ecol 62:29-38

Jorgensen BB. Des Marais DJ (1990) The diffusive boundary layer of sediments: oxygen microgradjents over a microbial mat. Limnol Oceanogr 35:1343-1355

Jorgensen BB, Revsbech NP (1985) Diffusive boundary layers and the oxygen uptake of sediments and detritus. Limnol Oceanogr 30:111-122

Jorgensen BB, Revsbech NP (1988) Microsensors. In: Packer L, Glazer AN (eds) Methods in enzymology. Academic Press, San Diego, p 639-659

Kühl M, Glud RN, Ploug H, Ramsing NB (1996) Microenvironmental control of photosynthesis and photosynthesiscoupled respiration in an epilithic cyanobacterial biofilm. J Phycol 32:799-812

Kühl M, Jørgensen BB (1994) The light field of microbenthic communities: radiance distribution and microscale optics of sandy coastal sediments. Limnol Oceanogr 39:1368-1398

Lassen C, Ploug H, Jorgensen BB (1992) Microalgal photosynthesis and spectral scalar irradiance in coastal marine sediments of Limfjorden, Denmark. Limnol Oceanogr 37 : $760-772$

Lohse L, Epping EHG, Helder W, van Raaphorst W (1996) Oxygen pore water profiles in continental shelf sediments of the North Sea: turbulent versus molecular diffusion. Mar Ecol Prog Ser 145:63-75

Mostajir B, Dolan J, Rassoulzadegan F (1995) A simple method for the quantification of a class of labile marine pico- and nano-sized detritus: DAPI Yellow Particles (DYP). Aquat Microb Ecol 9:259-266

Pinckney J, Zingmark RG (1991) Effects of tidal stage and sun angles on intertidal benthic microalgal productivity. Mar Ecol Prog Ser 76:81-89 
Porter KG, Feig YS (1980) The use of DAPI for identifying and counting aquatic microflora. Limnol Oceanogr 25:943-948

Reay WG, Gallagher DL, Simmons GM Jr (1995) Sedimentwater column oxygen and nutrient fluxes in nearshore environments of the lower Delmarva Peninsula, USA. Mar Ecol Prog Ser 118:215-227

Revsbech NP (1989) Diffusion characteristics of microbial communities determined by use of oxygen microsensors J Microbiol Methods 9:111-122

Revsbech NP, Jorgensen BB (1983) Photosynthesis of benthic microflora measured with high spatial resolution by the oxygen microprofile method: capabilities and limitations of the method. Limnol Oceanogr 28:749-756

Revsbech NP, Jørgensen BB (1986) Microelectrodes: their use in microbial ecology. Adv Microb Ecol 9:293-352

Revsbech NP, Serensen J, Blackburn TH, Lomholt JP (1980) Distribution of oxygen in marine sediments measured with microelectrodes. Limnol Oceanogr 25:403-411

Responsible Subject Editor: T H. Blackburn, Aarhus, Denmark
Shum KT (1995) A numerical study of the wave-induced solute transport above a rippled bed. J Fluid Mech 299: $267-288$

Strickland JD, Parsons TR (1972) A practical handbook of seawater analysis, 2nd edn. Bull Fish Res Bd Can 167

Sundbäck K. Enoksson V. Granéli W, Pettersson K (1991) Influence of sublittoral microphytobenthos on the oxygen and nutrient flux between sediment and water: a laboratory continuous-flow study. Mar Ecol Prog Ser 74: $263-279$

Yallop ML, de Winder B, Paterson DM, Stal LJ (1994) Comparative structure, primary production and biogenic stabilization of cohesive and non-cohesive marine sediments inhabited by microphytobenthos. Estuar Coast Shelf Sci 39:565-582

Ziebis W, Huettel M, Forster S (1996) Impact of biogenic sediment topography on oxygen fluxes in permeable seabeds. Mar Ecol Prog Ser 140:227-237

Manuscript first received: January 13,1997

Revised version accepted: March 18, 1997 